\section{Plan to close schools resisted}

London

THE review of veterinary science at British universities, published earlier this year, has been so fiercely attacked that it seems unlikely that its proposals will be implemented unchanged. The review (see Nature 337, 294; 26 January 1989) recommended that the veterinary schools at Glasgow and Cambridge should be closed.

Representatives of the veterinary profession now say that the closures will increase manpower shortages, lead to a lowering of standards in the veterinary profession and persuade more British researchers to go to the United States to work. In the universities, even those who agree that some reduction of capacity would be wise say the working party has picked the wrong targets.

The review is one of a series being carried out for the University Grants Committee in an attempt to decide how to use most efficiently the limited financial resources of Britain's universities. The working party for the veterinary sciences, whose chairman is Sir Ralph Riley, was told that a maximum intake of 335 students a year will be necessary to meet future manpower requirements and was asked to frame its recommendations accordingly.

To ensure that clinical sciences are taught with satisfactory spread and depth, the working party concluded that each school should have at least 36 clinical teachers. With some redistribution of posts, four schools, instead of the present six, would be sufficient. In order that the remaining schools are as widely spaced geographically as possible, the working party concluded that one of the two schools in Scotland and one in the SouthEast of England would have to be closed down.

Because there is room for expansion at Edinburgh, the Glasgow school was selected for closure. But the review says that the Edinburgh school should cease to exist in name, and that a new Scottish school would be formed by a merger of the two.

The Royal College of Veterinary Surgeons and the British Veterinary Association last week launched a furious attack on these proposals. They argue that future manpower needs require an intake of 400-500 students a year, which four schools could not provide. The registrar of the college, Alistair Porter, says the shortage of veterinary surgeons has already brought an influx of manpower from other countries

The president of the Royal College, John Parsons, says that researchers would prefer to move to the United States rather than agree to be relocated in Britain. Since the announcement of the proposed closures in January, job offers have started coming in to researchers at Glasgow and Cambridge.

But those at the highly regarded department of veterinary pathology at the University of Glasgow are unlikely to be lured away. Even if the Glasgow school does move, there are provisions in the Riley report for this department to continue to exist at the University of Glasgow. The campaign against closure of the veterinary school in Glasgow has won widespread support in the local community: a petition with more than 300,000 signatures is to be sent to the prime minister.

Christine McGourty researchers may quit

\title{
Sydney
}

THE poor job market for Australian scientists is apparently starting to cause problems for the future of Australian science. The signs of trouble are clear from the figures for university enrolment for this academic year. According to a report by Australian Vice-Chancellors Committee, universities have had to lower entry standards to find enough science students. At the University of Sydney, entry scores in the science faculty dropped from $\mathbf{3 2 0}$ out of a possible 500 in 1987 to 300 this year, the lowest entry aggregate for any faculty. The University of Melbourne was forced to drop entry requirements from 295 in 1988 to 279 this year in order to fill its quota of science students.

But even those already on the career ladder are finding the climb tough. Seventyfive per cent of non-tenured Commonwealth Scientific and Industrial Research Organisation (CSIRO) scientists are unhappy with their career prospects, according to a survey by the recently formed Australian Science Action group, headed by Dr Greg Tanner, a CSIRO plant scientist. Forty per cent of the total sample size of $\mathbf{1 7 5}$ say they are prepared to leave Australia. Of these, 28 per cent indicated that they would pursue science overseas, while the rest say they would leave science altogether.

The CSIRO study shows that disillusion is greatest among younger postdoctoral researchers without tenure. The disaffection is particularly striking among biologists and chemists; those in the physical sciences less commonly regarded their prospects as poor. Women scientists with families are also discouraged about staying in science because of the reduced number of part-time positions available.

Tania Ewing

\section{Voyager's first glimpse of distant planet raises NASA's hopes}

Prospects for Voyager 2's fly-by of Neptune on 24 August are encouraging, according to the mission controllers at the Jet Propulsion Laboratory in Pasadena. The colour images shown here, taken on 23 January when Voyager was about 185 million miles ( 309 million $\mathrm{km}$ ) from the planet, already show detail down to 3,500 miles $(6,000 \mathrm{~km})$, better than that available from the best telescope images from Earth. The fact that distinct cloud features are visible when the spacecraft is still so distant suggests that images obtained during August will show far more detail than was visible in the atmosphere of Uranus, which Voyager 2 encountered in January 1986. The natural colour of Neptune, like that of Uranus, is a pale blue-green, caused by methane gas in the atmosphere, which absorbs red light. The images here were obtained through violet, clear and orange filters.
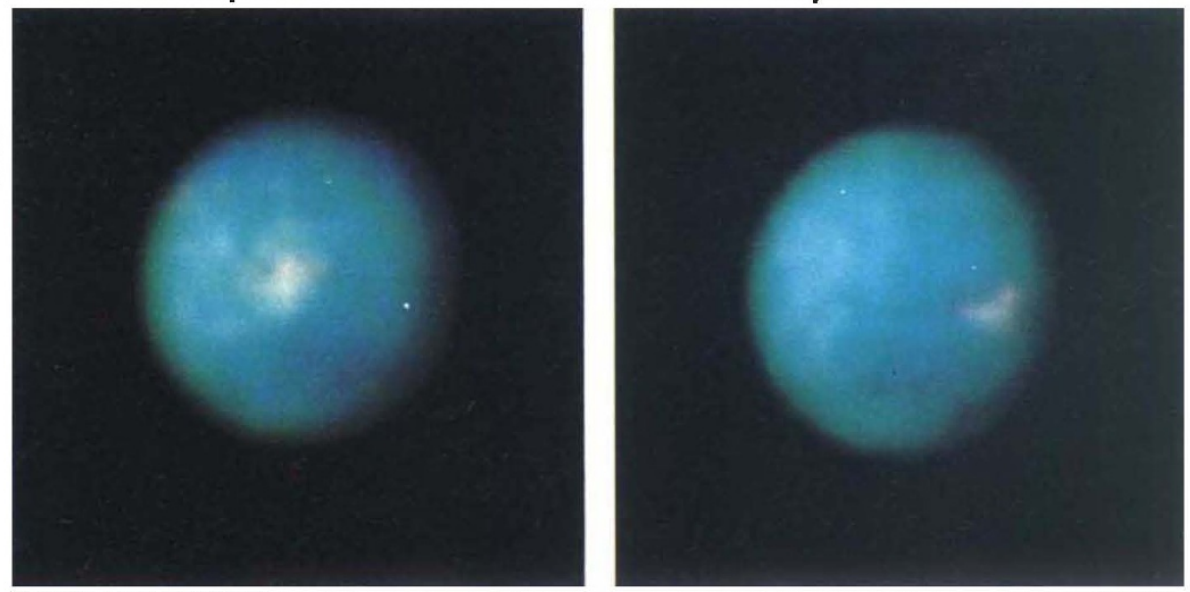

Two images of Neptune taken about 2 hours apart. The bright cloud feature visible near the centre of Neptune's disk in the earlier (left-hand) image has moved to the right edge of the planet in the later image. This is in line with the 17- to 18-hour rotation calculated from Earth-based observations. A dark band of clouds, similar to structures seen on Jupiter, Saturn and Uranus, can be seen encircling the southern pole. 